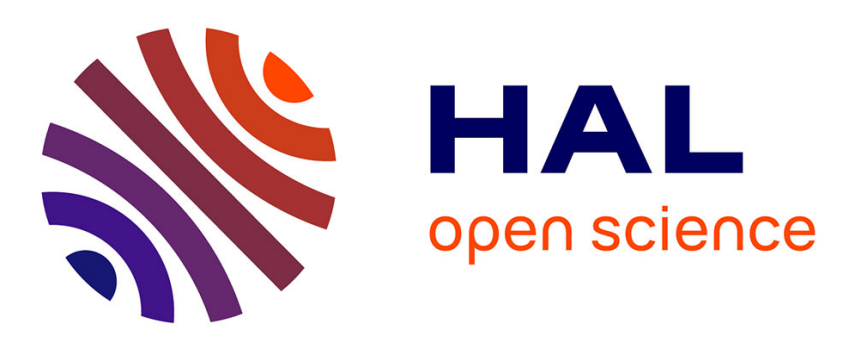

\title{
Emotion and Prejudice: Specific Emotions Toward Outgroups
}

Molly Parker Tapias, Jack Glaser, Dacher Keltner, Kristen Vasquez, Thomas

Wickens

\section{- To cite this version:}

Molly Parker Tapias, Jack Glaser, Dacher Keltner, Kristen Vasquez, Thomas Wickens. Emotion and Prejudice: Specific Emotions Toward Outgroups. Group Processes and Intergroup Relations, 2007, 10 (1), pp.27-39. 10.1177/1368430207071338 . hal-00571637

\section{HAL Id: hal-00571637 https://hal.science/hal-00571637}

Submitted on 1 Mar 2011

HAL is a multi-disciplinary open access archive for the deposit and dissemination of scientific research documents, whether they are published or not. The documents may come from teaching and research institutions in France or abroad, or from public or private research centers.
L'archive ouverte pluridisciplinaire HAL, est destinée au dépôt et à la diffusion de documents scientifiques de niveau recherche, publiés ou non, émanant des établissements d'enseignement et de recherche français ou étrangers, des laboratoires publics ou privés. 


\title{
Emotion and Prejudice: Specific Emotions Toward Outgroups
}

\author{
Molly Parker Tapias, Jack Glaser and Dacher Keltner \\ University of California, Berkeley
}

Kristen Vasquez

Alverno College

Thomas Wickens

University of California, Berkeley

\begin{abstract}
This research draws on ideas about emotion-related appraisal tendencies to generate and test novel propositions about intergroup emotions. First, emotion elicited by outgroup category activation can be transferred to an unrelated stimulus (incidental emotion effects). Second, people predisposed toward an emotion are more prejudiced toward groups that are likely to be associated with that emotion. Discussion focuses on the implications of the studies for a more complete understanding of the nature of prejudice, and specifically, the different qualities of prejudice for different target groups.
\end{abstract}

KEYWORDS emotion, prejudice, stereotypes

RECENTLY, researchers from divergent traditions have explored how bias toward outgroups can be manifested as different emotions (e.g. Cottrell \& Neuberg, 2005; Fiske, Cuddy, Glick, \& Xu, 2002; Mackie, Devos, \& Smith, 2000; Smith, 1993). For example, researchers in the stereotype tradition have linked stereotypes of incompetence or interpersonal aloofness to pity, contempt, or envy (Fiske et al., 2002). From another perspective, researchers focusing on contextspecific judgments showed that perceptions of outgroup strength or weakness relative to the ingroup generated different negative emotions, such as anger, disgust, or fear (Mackie et al., 2000). Still others have illustrated differences in emotion toward outgroups by examining responsibility and blame perceptions (Weiner, Perry, \& Magnusson, 1988) or archetypal images of barbarian, enemy, and imperialist (Alexander, Brewer, \& Herrmann, 1999).

One study has specifically linked appraisals and distinct emotions toward outgroups. Cottrell and Neuberg (2005) focused on a specific kind of appraisal-threat-and distinct emotions toward outgroups. They predicted and found correlational evidence for the notion that outgroups activate specific threats, such as contamination or harm, and these threats are associated with distinct emotions, such as

\footnotetext{
$\overline{\text { Author's note }}$

Address correspondence to: Jack Glaser, Goldman School of Public Policy, University of California, Berkeley, 2607 Hearst Avenue, Berkeley, CA 94720-7320, USA [email: jackglaser@berkeley.edu]
} 
disgust or anger, respectively. They argue that intergroup emotions are activated by threat appraisals, specifically, because groups pose evolutionarily significant 'socio-functional threats', including competition for resources, attack, disease, and non-reciprocation. The present two studies extend this reasoning and its related findings to the study of individual differences in emotion and prejudice, and to the possibility that stereotypes prime emotional responses to unrelated stimuli.

\section{Prejudice from an emotion perspective}

Emotions are assumed to be responses to cognitive appraisals (Frijda, Kuipers, \& ter Schure, 1989; Lazarus, 1991; Smith \& Ellsworth, 1985). Specifically, appraisals are ways of perceiving people or events according to evolutionarily significant themes, such as attack, loss, or disease. In addition to physical survival and reproduction, appraisals are attuned to socialmoral problems, such as injustice, impurity, and greed (Giner-Sorolla \& Gutierrez, 2005; Haidt, 2003; Haidt, Koller, \& Dias, 1993; Lazarus, 1991; Rozin, Lowery, Imada, \& Haidt, 1999; Weiner, 1993). For example, an appraisal of a person as behaving in a lazy, irresponsible, or unfair way tends to elicit anger (Lazarus, 1991; Shaver, Schwartz, Kirson, \& O'Connor, 1987; Weiner et al., 1988). Outgroups may elicit emotion by activating either type of appraisal, relating to a basic appraisal theme (e.g. contagion eliciting disgust) or a socio-moral theme (e.g. violations of community norms eliciting contempt).

Advances in the study of emotion generate at least three general predictions relevant to the study of emotion and prejudice. First is that perceptions of specific groups and their attendant stereotypes elicit distinct emotional responses. This thesis has been explored with a great deal of success in the past 10 years (e.g. Cottrell \& Neuberg, 2005; Fiske et al., 2002; Smith, 1993). ${ }^{1}$

The second proposition, which we tested in Study 1 , is that emotion elicited by an outgroup can be transferred to unrelated stimuli. This phenomenon is known as incidental emotion.
Studies of incidental effects of emotion have found that emotions, most notably anger, sadness, fear, and disgust, influence judgments of stimuli unrelated to the elicitor of the emotion in ways that are congruent with that emotion's appraisal theme (DeSteno, Dasgupta, Bartlett, \& Cajdric, 2004; Keltner, Ellsworth, \& Edwards, 1993; Lerner \& Keltner, 2000, 2001; Tiedens \& Linton, 2001). The broad implication of this proposition is that reactions to outgroups should influence emotions toward any people, events, and objects encountered after the outgroup category is activated. The incidental emotion should be specific to the appraisal tendency and emotion originally activated by the outgroup. In other words, an anger-eliciting group should potentiate anger toward unrelated stimuli, whereas a disgust-eliciting group should potentiate disgust toward the same stimuli. Furthermore, differential emotional responses to ostensibly unrelated stimuli can be used to infer the content of the emotional response to the groups who are primed.

A third thesis is that individuals predisposed toward an emotion should be more prejudiced toward outgroups whose stereotypic traits would be likely to elicit that emotion. An emotional disposition reflects a tendency toward more frequent episodes, more intense experiences, and more intense expressions of a particular emotion (Kagan \& Snidman, 1991; Malatesta, 1990; Spielberger, Sydeman, Owen, \& Marsh, 1999). Based on an appraisal tendency perspective, an emotional disposition should be associated with a heightened tendency to construe events, objects, and people in line with the appraisal tendency associated with that emotion (Lerner \& Keltner, 2000, 2001). With regard to outgroups, individuals predisposed toward an emotion are likely to be more prejudiced, that is, experience more frequent and intense affect, toward groups that tend to activate the emotion. For example, anger-prone individuals would be more prejudiced toward groups that activate anger-related appraisals (e.g. harm, injustice). Evidence in support of this proposition, which we pursue in Study 2, advances the field in two ways, in that it helps to explain individual differences in prejudice 
while bolstering the evidence for differentiation in emotional reactions to outgroups.

We hypothesized that priming thoughts of African-Americans would tend to elicit anger in response to unrelated stimuli in Study 1 and prejudice against Blacks would be associated with dispositional anger in Study 2. These predictions were based on appraisal research, which has shown that injustice appraisals evoke anger (e.g. Rozin et al., 1999; Vasquez, Keltner, Ebenbach, \& Banaszynski, 2001), and justice-related themes of stereotypes of African-Americans (e.g. Devine, 1989), such as 'low-achieving' and 'free-loading'. These predictions also follow from previous studies, which have documented associations between stereotypes of African-Americans and anger. Prejudice toward African-Americans has been associated with anger, in terms of self-reported emotion (Cottrell \& Neuberg, 2005; Stephan \& Stephan, 1985), and measured changes in facial musculature, where Whites who viewed African-American faces showed changes in the corrugator supercilii associated with anger (Vanman, Paul, Ito, \& Miller, 1997; Vanman, Saltz, Nathan, Warren, 2004).

We hypothesized that the gay stereotype would be associated with disgust, given the centrality of impurity to both the gay stereotype (e.g. 'diseased', 'abnormal', 'inappropriate sexuality') and disgust (Haidt, Rozin, McCauley, \& Imada, 1997; Rozin et al., 1999; Vasquez et al., 2001). This hypothesis is supported, directly and implicitly, by studies of anti-gay attitudes and affect. People asked to describe their spontaneous reactions toward homosexuality indicate feeling 'disgust' (Guth et al., 2001; Haddock, Zanna, \& Esses, 1993; Haidt \& Hersh, 2001). More implicitly, measures of anti-gay attitudes often include an item assessing 'disgust' toward gays or same-sex sexual behavior (Frable, Wortman, \& Joseph, 1997; Herek, 1994; LaMar \& Kite, 1998; Larsen, Reed, \& Hoffman, 1980). Individuals predisposed toward experiencing disgust tend to report prejudice toward gays (Ernulf \& Innala, 1987; Haidt, McCauley, \& Rozin, 1994; Olatunji, Lohr, \& Meunier, 2002; Van de Ven, Bornholt, \& Bailey, 1996). As another example, Cottrell and Neuberg (2005) found that gays were perceived as a contamination threat, by threatening disease and, more metaphorically, by threatening traditional values. Furthermore, Cottrell and Neuberg (2005) found the perception of gays as a contamination threat was associated with disgust and pity toward the group.

\section{Study 1: Incidental emotion resulting from priming of groups}

In Study 1, we ask whether thinking about African-Americans and gays will actually lead to incidental effects of anger and disgust, respectively, on the interpretation of unrelated stimuli. Our reasoning is that over time outgroups become chronically linked with specific emotions through repeated association of the stereotype and the emotion-related appraisal. Once an association is formed, exposure to any outgroup cue (e.g. a label or image) should activate the appraisal and elicit the corresponding emotion, without requiring direct activation of the stereotype. Study 1 tests this by priming outgroups with stimuli devoid of stereotype content and examining subsequent emotional reactions.

Previous studies have found that emotions, most notably anger, sadness, fear, and disgust, influence judgments of stimuli unrelated to the elicitor of the emotion in ways that are congruent with the emotion's underlying appraisal tendency (DeSteno et al., 2004; Keltner et al., 1993; Lerner \& Keltner, 2000, 2001; Tiedens \& Linton, 2001). With respect to prejudice, this suggests that exposure to African-American primes should evoke greater anger, and exposure to gay primes should evoke greater disgust, in response to the unrelated stimuli.

Select studies suggest that prejudice toward African-Americans produces incidental anger. In a study assessing automatic stereotype activation, European-Americans were exposed to subliminally presented African-American or European-American faces and their behavior was assessed in response to a vexatious request by a confederate (Bargh, Chen, \& Burrows, 1996). Participants primed with African-American faces responded to the request with more hostile behavior, which may have resulted from the activation and self-application of the hostile 
Black stereotype, or the activation of an anger response to the Black group. Research on prejudice and facial perception finds that implicit prejudice toward African-Americans facilitates perceiving anger in African-American faces and not in European-American faces (Hugenberg \& Bodenhausen, 2003). Whether thinking about African-Americans causes anger was not tested. No known study provides precedent regarding incidental emotions following activation of thoughts about gays.

In Study 1, we measured participants' emotions toward an unrelated stimulus after exposing them to outgroup priming. Based on past research and the appraisal tendency model, we expected African-American priming to lead to incidental anger and fear. In contrast, gay priming should lead to incidental disgust and, to a lesser extent, anger. We predicted that outgroup priming would produce no significant differences in the other emotions assessed (contempt, guilt, sympathy, and shame), despite these emotions being implicated in other models of intergroup emotions, because these emotions are not primarily implicated in appraisals of the groups we primed.

\section{Method}

Participants The sample included 115 undergraduate participants (60 males and 55 females) recruited from the psychology research participant pool at the University of California, Berkeley. They received partial course credit for completing the study. Participants were on average 20.1 years old $(S D=2.1)$. The sample included 31 Caucasian students, 47 East Asian students, 18 Southeast Asian students, 10 Latino students, 6 students of mixed race/ethnicity, and 3 students who did not specify their race/ ethnicity.

Procedure Participants were divided into two conditions, one condition priming AfricanAmerican males and another condition priming gay males. The prime consisted of unscrambling word sets to form sentences that involved AfricanAmerican males $(n=60)$ or gay males $(n=55)$. Participants each unscrambled 20 sentences, 15 of which referred to the target group and 5 of which were fillers. The primes were designed to activate the group construct. An example of an African-American prime is the word set 'being identifies as Deion for Black', which read unscrambled, with the extra word ('for') eliminated, 'Deion identifies as being Black'. One of the gay male primes was 'to a gay club John goes dance from', which unscrambles to, 'John goes to a gay dance club'. Another gay male prime was, unscrambled, 'Drew joins a gay chatroom'. As these examples illustrate, the primes directly activated the idea of the group, and a few also mentioned behaviors that participants may have construed as characteristic, but did not directly activate the emotions hypothesized to be associated with the groups.

After the priming, in an ostensibly unrelated task, participants were randomly assigned to read one of two brief stories that were designed, and determined through pilot testing, to describe a person behaving in ways that could evoke anger, disgust, and/or fear. The race/ethnicity and sexual orientation of the person in the story was indeterminate. Participants were asked to indicate their emotional response to the story and to describe the protagonist in five words or phrases. Participants reported no awareness of a connection between the priming and emotion ratings. At the end of the study, participants were debriefed and given course credit for their participation.

The purpose of the study was to determine if group priming elicits emotional reactions which, in turn, may be incidentally attributed to an unrelated stimulus. Accordingly, the target stimulus stories were developed to allow for comparable attributions of anger, disgust, and fear. One story $(n=57)$ described the participant as working to help pay for college. The participant's work supervisor suggests that he may have to lay off the participant (intended to resonate with a fear response). Then the supervisor trips over machinery, which rips open his leg, exposing bone and gushing blood (disgust). After spending the day obtaining medical care for the supervisor, the supervisor tells the participant that he gave away the participant's promotion to his own son (anger). The other story $(n=58)$ described the 
participant walking by a homeless man on the street late at night. The homeless man reeks of body odor, urine, and vomit (disgust). He jumps at the participant, demanding his or her wallet (fear). The participant gives it to him, losing the only money the participant has to buy presents for the holidays (anger).

Emotion ratings Participants rated how much anger, fear, disgust, contempt, sympathy, shame, and guilt they experienced, after reading the story, on scales ranging from 0 (no emotion) to 6 (extreme emotion).

\section{Results}

We predicted that priming the African-American category would elicit more anger and fear than other emotions, and priming the gay male category would elicit more disgust and to a lesser extent, anger, than other emotions in response to the target story. We examined the effect of priming on anger, disgust, and fear ratings by conducting mixed-factor analysis of covariance (ANCOVA) analyses on emotion ratings, testing for the interaction of prime and emotion. Story version was entered as a covariate because the stories evoked different levels of anger, disgust, and fear. ${ }^{2}$ Because women sometimes report feeling more intense emotion than men do (Choti, Marston, Holston, \& Hart, 1987; Greenwald, Cook, \& Lang, 1989; Schwartz, Brown, \& Ahern, 1980), we checked whether emotion ratings differed by gender. Men and women did not differ significantly in their ratings of contempt, sympathy, shame, or guilt, but, consistent with previous studies, women reported significantly more anger and fear, and marginally significantly more disgust, than men. ${ }^{3}$ Accordingly, gender was entered as a covariate in the analyses.

To isolate the effect of group priming on just anger and disgust, a mixed-factor ANCOVA was conducted on emotion ratings with prime, type of emotion, and the theoretically relevant interactions as predictors, and story version and participant gender as covariates. The interaction of critical interest to our predictions, the interaction of emotion type (anger versus disgust) and outgroup prime, was significant $(F(1,108)=5.43, p<.05)$. Simple comparisons revealed that the African-American prime elicited significantly more anger $(M=3.87$, $S D=1.81)$ than disgust $(M=3.40, S D=1.92)$ $(t(59)=-2.45, p<.05)$ (See Table 1$)$. In contrast, the gay prime elicited comparable levels of anger $(M=4.09, S D=1.83)$ and disgust $(M=4.04$, $S D=1.81)(t(53)=-0.25, n s)$. Furthermore, the gay prime elicited marginally significantly more disgust than did the African-American prime $(t(112)=1.82, p=.07) .^{4}$

Relatively low levels of fear were reported in response to both primes. Given that caveat, we tested the pattern of fear and disgust as a function of priming by conducting a mixed-factor ANCOVA on fear and disgust ratings with prime, emotion, and their interaction as predictors, and story version and participant gender as covariates. The analysis revealed no significant

Table 1. Emotions elicited by outgroup priming, Study $1(N=114)$

\begin{tabular}{lcccr}
\hline & \multicolumn{2}{c}{ Means by prime } & \multicolumn{2}{c}{ Comparison by prime* } \\
\cline { 2 - 4 } Emotion & African-American & Gay & $t$ & $p$ \\
\hline Anger & $3.87_{\mathrm{a}}$ & $4.09_{\mathrm{a}}$ & 0.61 & .54 \\
Disgust & $3.40_{\mathrm{b}}$ & $4.04_{\mathrm{a}}$ & 1.82 & .07 \\
Fear & $2.05_{\mathrm{c}}$ & $2.87_{\mathrm{bc}}$ & .04 \\
Contempt & $3.27_{\mathrm{b}}$ & $3.25_{\mathrm{b}}$ & 2.11 & .96 \\
Sympathy & $2.37_{\mathrm{c}}$ & $2.31_{\mathrm{c}}$ & -0.05 & .87 \\
Shame & $0.93_{\mathrm{d}}$ & $1.62_{\mathrm{d}}$ & -0.17 & .02 \\
Guilt & $0.70_{\mathrm{d}}$ & $1.31_{\mathrm{d}}$ & 2.38 & .02 \\
\hline
\end{tabular}

* Means in the same row were analyzed by $t$ test for equality of means. Means in the same column that do not share subscripts differ significantly $p<.05$ in the $t$ test for equality of means. 
interaction of emotion (fear versus disgust) and outgroup prime $(F(1,110)=1.64, n s)$, nor a significant main effect of prime $(F(1,110)=$ $2.40, n s)$. Simple comparisons revealed that the gay prime elicited significantly more fear $(M=2.87, S D=2.06)$ than the African-American prime $(M=2.05, S D=2.13)(t(113)=2.11$, $p<.05)$. As noted earlier, the gay prime elicited marginally significantly more disgust than the African-American prime. ${ }^{5}$

We would have additional support for the emotion specificity hypothesis if other emotions included in the study-contempt, sympathy, guilt, and shame-did not differ significantly by outgroup priming. In line with this prediction, there were no significant differences in contempt or sympathy as a function of priming. Shame and guilt, however, were higher following the gay prime than the African-American prime, though participants reported relatively low levels of these emotions overall.

\section{Discussion}

Study 1 demonstrated that outgroups can spontaneously elicit specific emotions without directly activating stereotypes or appraisals associated with those emotions. Furthermore, this study tested whether intergroup emotions can have incidental effects on perceptions of unrelated stimuli. As predicted, the outgroup primes elicited different patterns of incidental emotions. The African-American prime elicited more anger than any other emotion assessed. The gay prime elicited high levels of disgust and anger, and more disgust than did the AfricanAmerican prime. Fear was significantly higher in response to the gay prime, though relatively low levels of fear were reported in response to both primes. In retrospect, asking participants to report experiencing fear in response to a hypothetical situation is problematic, fear being an emotion that may be less prone to vicarious experience than other emotions (see also Mackie et al., 2000).

That the two primes elicited similar levels of contempt and sympathy provides further support for emotion specificity in prejudice because these emotions are not expected to be differentially associated with the primed groups, providing a basis for comparison. The finding that incidental contempt did not differ by outgroup priming was particularly important for several reasons. First, this is the first study of intergroup emotion to distinguish contempt toward outgroups from other negative emotions such as anger, disgust, and fear. Other studies have examined contempt in combination with anger (Fiske et al., 2002) or fear (Mackie et al., 2000), and have therefore not been able to differentiate contempt from other emotions, as Study $1 \mathrm{did}$. Second, contempt was one of several emotions that did not reveal a main effect of emotional intensity by outgroup prime. Emotions were generally stronger in response to the gay prime than the African-American prime. However, contempt as well as sympathy yielded no such difference, providing further evidence that emotional responses to outgroups are differentiated, not just yoked to overall negative affect.

Based on our findings in Study 1, we expect prejudice leads to other emotion-specific incidental effects, in addition to the experience of emotions and interpretation of stimuli in line with particular appraisal tendencies. For example, outgroup-elicited emotion could activate incidental action tendencies congruent with the emotion, such as hostile behavior following exposure to an anger-eliciting outgroup (e.g. Bargh et al., 1996). As another example, prejudice could elicit emotion-specific responses in the autonomic nervous system (Levenson, Ekman, \& Friesen, 1990).

\section{Study 2: Individual differences in emotion and prejudice}

Thus far, we have seen that activating thoughts of different outgroups leads to differential emotional reactions to subsequent stimuli, providing evidence for incidental emotion in intergroup perceptions and group-emotion specificity in prejudice. In Study 2, we sought further evidence of group-emotion specificity in prejudice by assessing whether individuals predisposed to experiencing an emotion are more prejudiced toward outgroups whose stereotypes and attendant appraisals are associated with the 
emotion. We expect that anger-prone individuals are likely to be more prejudiced toward groups associated with that emotion's appraisals (harm or injustice), such as African-Americans, and not toward groups associated with other appraisals. We further predict that disgust-prone people would be more prejudiced toward groups associated with that emotion's appraisals (impurity or contamination), such as gay men. Though not tested in comparison with other emotional dispositions, disgust sensitivity has been associated with prejudice toward gays (Ernulf \& Innala, 1987; Haidt et al., 1994; Olatunji et al., 2002; Van de Ven et al., 1996).

\section{Method}

Participants The sample consisted of 81 undergraduate males recruited from the psychology participant pool at the University of California, Berkeley. Only males were included in the study because pilot testing revealed that males and females differed significantly on both the predictors (anger and disgust proneness) and dependent outcomes (prejudice toward African-Americans and gay males). Participants received partial course credit for the study. Participants were on average 19.7 years old $(S D=1.6)$ and included 40 Asian students, 39 Caucasian students, and 2 Middle Eastern students. African-American, gay, or bisexual students were not recruited; all 81 participants reported being heterosexual.

Procedure Participants completed a questionnaire that contained measures of dispositions for anger and disgust, prejudice toward African-Americans and gay males, and other measures described below. Participants were then debriefed and given course credit for their participation.

\section{Measures}

Emotional disposition Participants completed the 32-item Disgust Scale, Version 2 (Haidt et al., 1994), which assessed differences in disgust sensitivity (e.g. 'It would make me uncomfortable to hear a couple making love in the next room of a hotel'). The scale assessed four domains: sex, death/envelope violations, interpersonal, and core disgust. Reliability was high for the total scale $(\alpha=.88)$ and moderately high for subscales (Sex $\alpha=.79$, Death $\alpha=.72$, Interpersonal $\alpha=.80$, and Core $\alpha=.59$ ). Items were rated on 4-point Likert scales. Half of the items were labeled Strongly disagree (1) to Strongly agree (4); half were labeled Not disgusting at all (1) to Very disgusting (4).

Participants completed the 20-item Trait Anger scale (a subscale of the State-Trait Anger Expression Inventory; Spielberger, 1996), which assessed a disposition to experience angry feelings as a personality trait (e.g. 'I feel infuriated when I do a good job and get a poor evaluation'). Items were rated on 4-point Likert scales $(1=$ Almost never, $4=$ Almost always). Ratings were averaged to create a reliable composite index $(\alpha=.83)$. Trait anger scores were significantly positively correlated with disgust sensitivity $(r(81)=.32$, $p<.01)$ and sex-related disgust sensitivity $(r(81)=$ $.32, p<.01)$.

Prejudice toward African-Americans Participants completed the 10-item Anti-Black Attitudes Scale (Katz \& Hass, 1988), including items such as, 'The root cause of most of the social and economic ills of blacks is the weakness and instability of a black family'. Items were rated on 5-point Likert scales $(1=$ Strongly disagree, $5=$ Strongly agree $)$. The measure showed good reliability $(\alpha=.83)$.

Prejudice toward gay males Participants completed the 10-item Attitudes toward Gay Men scale (Herek, 1988), including items such as, 'Homosexual behavior between two men is just plain wrong'. Items were rated on 5-point Likert scales $(1=$ Strongly disagree, $5=$ Strongly agree $)$. The measure showed high reliability $(\alpha=.89)$. Anti-gay attitudes were further assessed by subscales of the Components of Attitudes toward Homosexuality scale (LaMar \& Kite, 1998). The Gay Male Stereotypes subscale consists of seven items that assess people's stereotypes about gay males (e.g. 'Most gay men have a life of one night stands'). To assess anxiety about attraction and sexual advances from members of the same sex, four items were used from the 14-item Contact subscale (e.g. 'I would feel 
uncomfortable if a member of my sex made an advance toward me'). Items were rated on 5-point Likert scales $(1=$ Strongly disagree, $5=$ Strongly agree $)$. Stereotype $(\alpha=.64)$ and Contact $(\alpha=.73)$ subscales showed reasonable reliability and were marginally positively correlated $(r(81)=0.20$, $p=.07)$. All measures of gay prejudice were significantly positively correlated (average $r(81)=$ .42 , minimum $r(81)=.2$, maximum $r(81)=.58$ ). Scale scores for Anti-Gay Attitudes, Contact, and Stereotypes were standardized and averaged to form a composite index of prejudice against gay males $(\alpha=.68)$.

Ideology Conservatism has been associated with prejudice toward many outgroups, including African-Americans (Sears \& Henry, 2003; Sidanius, Pratto, \& Bobo, 1996) and gays (Herek, 2000; Whitley, 1999). Thus, we assessed political ideology in order to control for its effects. Participants completed a single-item measure of liberal-conservative ideology: 'With regard to political ideology, where would you place yourself on the following scale from extremely liberal to extremely conservative?' (adapted from the National Election Survey; National Election Studies, 2004). Such direct measures of ideology are known to have good construct validity (Knight, 1999). The item was rated on a 7-point Likert scale $(1=$ Extremely liberal, $4=$ Moderate, $7=$ Extremely conservative) .

\section{Results}

We examined the effects of predisposition toward anger (trait anger) and disgust (sexrelated disgust sensitivity), ${ }^{6}$ as well as ideology on prejudice toward African-Americans and gay males. Thus, trait anger, sex-related disgust sensitivity, and ideology were entered into simultaneous regression analyses predicting prejudice toward these groups.

Anger and anti-Black prejudice We predicted emotion specificity for anti-Black prejudice in that a predisposition toward anger, and not toward disgust, would relate to stronger prejudice toward African-Americans. To test this hypothesis, we conducted a simultaneous regression analysis on the Anti-Black Attitudes measure, with trait anger, sex-related disgust sensitivity, and ideology as predictors. ${ }^{7}$ In line with our hypothesis, trait anger was a significant predictor $(\beta=.23, p<$ .05 , one-tailed) of anti-Black prejudice, whereas there was a very small, nonsignificant effect of sex-related disgust sensitivity $(\beta=.05, n s)$ (See Table 2).

Disgust and gay male prejudice We also predicted emotion specificity for anti-gay prejudice, in that a predisposition toward disgust, and not toward anger, would relate to stronger prejudice against gay males. We conducted a simultaneous regression on the gay male prejudice composite, as was described for anti-Black prejudice. As predicted, sex disgust was a strong predictor $(\beta=.38$, $p<.001$, one-tailed), whereas the effect of trait anger was not significant $(\beta=.11, n s){ }^{8}$

Ideology Ideology had a marginally significant main effect on anti-Black attitudes $(\beta=.21, p=$ .07 , two-tailed), in line with previous research (e.g. Sears \& Henry, 2003; Sidanius et al., 1996),

Table 2. Summary of simultaneous regression analyses for individual differences in emotional disposition and ideology predicting prejudice, Study $2(N=81)$

\begin{tabular}{|c|c|c|c|c|}
\hline \multirow[b]{3}{*}{ Variable } & \multicolumn{4}{|c|}{ Prejudice } \\
\hline & \multicolumn{2}{|c|}{ African-American } & \multicolumn{2}{|c|}{ Gay } \\
\hline & $B$ & $\beta$ & $B$ & $\beta$ \\
\hline Trait anger & .15 & $.23 *^{\mathrm{a}}$ & .09 & .11 \\
\hline Sex-related disgust sensitivity & .03 & .05 & .30 & $.38 * * *^{\mathrm{a}}$ \\
\hline Ideology & .14 & $.21^{\dagger}$ & .24 & $.31 * * *$ \\
\hline
\end{tabular}

$* p<.05 ; * * p<.01 ; * * * p<.001 ;{ }^{\dagger} p<.1 . * p^{\text {a }}$ One-tailed. 
and a significant main effect on anti-gay attitudes $(\beta=.31, p<.01)$, replicating other studies of antigay attitudes (Herek, 2000; Whitley, 1999).

\section{Discussion}

Study 2 yielded evidence that prejudice is associated with specific emotions toward outgroups. Prejudice toward African-Americans is primarily associated with the disposition to experience anger, whereas prejudice toward gay males is associated with the disposition to experience disgust. More conservative political attitudes related to stronger prejudice against both African-Americans and gay males, regardless of male participants' predisposition toward anger or disgust.

\section{General discussion}

Guided by conceptual models of relations between outgroup bias and distinct emotion (e.g. Smith, 1993), we conducted two studies that examined hypothesized associations between prejudice, toward African Americans and gays, and emotions, particularly anger and disgust. In Study 1, indirect priming of African Americans led to relatively high anger experiences in response to subsequently presented stimuli, whereas exposure to the gay primes elicited disgust, and to a lesser extent, anger, although anger was not greater in response to Black primes than gay primes, in contradiction of our prediction. In Study 2, individual differences in anger and disgust were differentially related to prejudice toward African Americans and gays, respectively. The present studies build upon previous research linking African American stereotypes with anger and gay stereotypes with disgust (Cottrell \& Neuberg, 2005) by showing that groups can prime emotional reactions to unrelated stimuli and that these associations are evident at the trait or disposition level.

Evidence for disgust toward gays was revealed by incidental disgust following gay priming in Study 1 and the close relationship between disgust sensitivity and anti-gay attitudes in Study 2. Study 1 also revealed a relationship between anger and prejudice toward gays, in line with studies of heterosexual male homophobia and aggression toward gay men (e.g. Bernat, Calhoun, Adams, \& Zeichner, 2001). Future research should explore the extent to which prejudice toward gays, in particular among heterosexual men, elicits anger, either in combination with or in lieu of disgust.

Although the findings were promising, it is important to bear in mind their limitations. For example, while the present research found a relationship between prejudice toward AfricanAmericans and anger, Study 1 revealed at least as much anger toward the other primed outgroup too. Furthermore, the effects on fear responses in Study 1 were not as predicted.

Future studies should attempt to replicate these relationships and show generalizability to related outcomes, such as emotion-related psychophysiology, behavioral tendencies, or incidental effects on judgment. One promising line for future research would be to examine how the role of specific emotions in prejudice could help explain the diversity of discriminatory behaviors enacted against outgroup members (Swim, Cohen, \& Hyers, 1998). The prevalence of intimidation and destruction in hate crimes targeting African-Americans (Federal Bureau of Investigation, 2004) may reflect an anger response and the inclination to exact retribution. That anti-gay hate crimes disproportionately involve physical assaults (Federal Bureau of Investigation, 2004), for example, may reflect a physical disgust response.

In addition to predicting overt behavior, a focus on emotions can sharpen studies of how prejudice plays out in more subtle, face-to-face interactions between members of different groups. In line with this proposition, studies of intergroup interactions show that outgroup members are frequently affected by ingroup members' nonverbal expressions (Blascovich, Mendes, Hunter, \& Lickel, 2000; Dovidio, Kawakami, \& Gaertner, 2002; Word, Zanna, \& Cooper, 1974). By specifying anger, fear, contempt, and disgust as distinct aspects of prejudice, behaviors as diverse as fleeing, attacking, avoiding eye contact, and refraining from touching, differentially associated with 
these emotions, should occur with different frequencies in responses to particular groups and should be interpreted differently. Prejudice, therefore, clearly has a more complex form than can be captured in a unidimensional 'valence' conceptualization. This complexity, to the extent that we can map and understand it, should yield more precise predictions and explanations of intergroup behavior.

\section{Notes}

1. In two pilot studies we established that traits used to describe various minority groups clustered into four primary groups (corresponding to Asians and Jews; Blacks, Disabled, and Homeless; Latinos and Native Americans; with Gays being in their own group) and that when the trait clusters used to describe these groups were presented without group identifying labels, participants indicated differential emotional responses to them (e.g. more anger and fear toward Black stereotypes; more contempt toward Gay and Jewish stereotypes).

2. Because the design was counterbalanced (except for some minor differences in the sizes of the groups), and because we were concentrating on interactions, this difference had no effect on our conclusion.

3. Women reported significantly more anger $(M=4.36, S D=1.59)$ than men $(M=3.60$, $S D=1.92)(t(113)=2.31, p<.05)$, and more fear $(M=3.05, S D=2.31)$ than men $(M=1.88$, $S D=1.78)(t(113)=3.06, p<.01)$. Women also reported marginally significantly more disgust $(M=4.05, S D=1.67)$ than men $(M=3.37$, $S D=2.03)(t(112)=1.95, p=.05)$.

4. There was a significant interaction of story version by emotion type indicating that the two story versions evoked differential differences in emotion responses $(F(1,108)=7.76$, $p<.01)$. Simple comparisons revealed that the supervisor story elicited equal levels of anger $(M=3.80, S D=1.78)$ and disgust $(M=3.84$, $S D=1.89)(t(55)=1.77, n s)$. The homeless story elicited more anger $(M=4.14, S D=1.84)$ than disgust $(M=3.57, S D=1.90)(t(57)=2.76$, $p<.01)$. Anger and disgust ratings did not differ significantly between the supervisor and homeless stories.

5. Significantly different levels of fear and disgust were evoked by story version $(F(1,110)=22.74$, $p<.001)$. Simple comparisons revealed that the homeless story elicited equal levels of fear $(M=3.31, S D=2.11)$ and disgust $(M=3.57$, $S D=1.90)(t(57)=-.90, n s)$. The supervisor story elicited more disgust $(M=3.84, S D=1.85)$ than fear $(M=1.55, S D=1.77)(t(55)=6.77$, $p<.001)$. Disgust ratings did not differ significantly between the supervisor and homeless stories. Fear ratings were significantly higher for the homeless story than for the supervisor story, $t(113)=4.83, p<.001)$.

6 . The same pattern of results was revealed when analyses were conducted using the full disgust sensitivity scale.

7. Interaction terms for ideology by trait anger and disgust were also included but were nonsignificant. Consequently, they are not included in the results reported here. Results did not differ as a function of presence of these interaction terms.

8. Because one item on Herek's Attitudes toward Gay Men scale explicitly references disgust and several others could be construed as implying it, we conducted a principal components factor analysis of all the questionnaire items to test if there was overlap between attitudes toward gays and disgust sensitivity. The results clearly indicated that these scales were independent, with no gay prejudice items loading on the sex disgust factor and only one sex disgust item, regarding daily masturbation, loading (0.52) somewhat mysteriously on the gay prejudice factor.

\section{References}

Alexander, M. G., Brewer, M. B., \& Herrmann, R. K. (1999). Images and affect: A functional analysis of out-group stereotypes. Journal of Personality and Social Psychology, 77, 78-93.

Bargh, J. A., Chen, M., \& Burrows, L. (1996). Automaticity of social behavior: Direct effects of trait construct and stereotype activation on action. Journal of Personality and Social Psychology, 71, 230-244.

Bernat, J. A., Calhoun, K. S., Adams, H. E., \& Zeichner, A. (2001). Homophobia and physical aggression toward homosexual and heterosexual individuals. Journal of Abnormal Psychology, 110, 179-187.

Blascovich, J., Mendes, W. B., Hunter, S., \& Lickel, B. (2000). Stigma, threat, and social interactions. In: T. F. Heatherton, R. E. Kleck, M. R. Hebl, \& 
J. G. Hull (Eds.), The social psychology of stigma (pp. 307-333). New York: Guilford.

Choti, S. E., Marston, A. R., Holston, S. G., \& Hart, J. T. (1987). Gender and personality variables in film-induced sadness and crying. Journal of Social and Clinical Psychology, 5, 535-544.

Cottrell, C. A., \& Neuberg, S. L. (2005). Different emotional reactions to different groups: A sociofunctional threat-based approach to 'prejudice.' Journal of Personality and Social Psychology, 88, 770-789.

DeSteno, D., Dasgupta, N., Bartlett, M. Y., \& Cajdric, A. (2004). Prejudice from thin air: The effect of emotion on automatic intergroup attitudes. Psychological Science, 15, 319-324.

Devine, P. G. (1989). Stereotypes and prejudice: Their automatic and controlled components. Journal of Personality and Social Psychology, 56, 5-18.

Dovidio, J. F., Kawakami, K., \& Gaertner, S. L. (2002). Implicit and explicit prejudice and interracial interaction. Journal of Personality and Social Psychology, 82, 62-68.

Ernulf, K. E., \& Innala, S. M. (1987). The relationship between affective and cognitive components of homophobic reaction. Archives of Sexual Behavior, 16, 501-509.

Federal Bureau of Investigation (2004). Hate crime statistics: 2003. Washington, DC: US Department of Justice.

Fiske, S. T., Cuddy, A. J., Glick, P., \& Xu, J. (2002). A model of (often mixed) stereotype content: Competence and warmth respectively follow from perceived status and competition. Journal of Personality and Social Psychology, 82, 878-902.

Frable, D.S., Wortman, C., \& Joseph, J. (1997). Predicting self-esteem, well-being, and distress in a cohort of gay men: The importance of cultural stigma, personal visibility, community networks, and positive identity. Journal of Personality, 65, 599-624.

Frijda, N. H., Kuipers, P., \& ter Schure, E. (1989). Relations among emotion, appraisal, and emotional action readiness. Journal of Personality and Social Psychology, 57, 212-228.

Giner-Sorolla, R., \& Gutierrez, R. (2005). Sick ... and wrong? Anger, disgust, and presumption of harm in reactions to taboo-breaking behaviors. Unpublished manuscript.

Greenwald, M. K., Cook, E. W., \& Lang, P. J. (1989). Affective judgment and psychophysiological response: Dimensional covariation in the evaluation of pictorial stimuli. Journal of Psychophysiology. 3, 51-64.
Guth, L. J., Lopez, D. F., Clements, K. D., \& Rojas, J. (2001). Student attitudes towards lesbian, gay, and bisexual issues: Analysis of self-talk categories. Journal of Homosexuality, 41, 137-156.

Haddock, G., Zanna, M. P., \& Esses, V. M. (1993). Assessing the structure of prejudicial attitudes: The case of attitudes toward homosexuals. Journal of Personality and Social Psychology, 65, 1105-1118.

Haidt, J. (2003). The moral emotions. In R. J. Davidson, K. R. Scherer, \& H. H. Goldsmith (Eds.), Handbook of affective sciences (pp. 852870). Oxford, UK: Oxford University Press.

Haidt, J., \& Hersh, M. A. (2001). Sexual morality: The cultures and reasons of liberals and conservatives. Journal of Applied Social Psychology, 31, 191-221.

Haidt, J., Koller, S. H., \& Dias, M. G. (1993) Affect, culture, and morality, or is it wrong to eat your dog? Journal of Personality and Social Psychology, 65, 613-628.

Haidt, J., McCauley, C. R., \& Rozin, P. (1994). Individual differences in sensitivity to disgust: A scale sampling seven domains of disgust elicitors. Personality and Individual Differences, 16, 701-713.

Haidt, J., Rozin, P., McCauley, C. R., \& Imada, S. (1997). Body, psyche, and culture: The relationship between disgust and morality. Psychology and Developing Societies, 9, 107-131.

Herek, G. M. (1988). Heterosexuals' attitudes toward lesbians and gay men: Correlates and gender differences. Journal of Sex Research, 25, 451-477.

Herek, G. M. (1994). Assessing heterosexuals' attitudes toward lesbians and gay men: A review of empirical research with the ATLG scale. In B. Greene \& G. M. Herek (Eds.), Lesbian and gay psychology: Theory, research, and clinical applications (pp. 206-228). Thousand Oaks, CA: Sage.

Herek, G. M. (2000). The psychology of sexual prejudice. Current Directions in Psychological Science, 9, 19-22.

Hugenberg, K., \& Bodenhausen, G. V. (2003). Facing prejudice: Implicit prejudice and the perception of facial threat. Psychological Science, 14, 640-643.

Kagan, J., \& Snidman, N. (1991). Temperamental factors in human development. American Psychologist, 46, 856-862.

Katz, I., \& Hass, R. G. (1988). Racial ambivalence and American value conflict: Correlational and priming studies of dual cognitive structures. Journal of Personality and Social Psychology, 55, 893-905. 
Keltner, D., Ellsworth, P.C., \& Edwards, K. (1993). Beyond simple pessimism: Effects of sadness and anger on social perception. Journal of Personality and Social Psychology, 64, 740-752.

Knight, K. (1999). Liberalism and conservatism. In J. P. Robinson, P. R. Shaver, \& L. S. Wrightsman (Eds.), Measures of political attitudes (pp. 59-158). San Diego, CA: Academic Press.

LaMar, L. A., \& Kite, M. E. (1998). Sex differences in attitudes toward gay men and lesbians: A multi-dimensional perspective. Journal of Sex Research, 35, 189-196

Larsen, K. S., Reed, M., \& Hoffman, S. (1980). Attitudes of heterosexuals toward homosexuality: A Likert-type scale and construct validity. Journal of Sex Research, 16, 245-257.

Lazarus, R. S. (1991). Emotion and adaptation. New York: Oxford University Press.

Lerner, J. S., \& Keltner, D. (2000). Beyond valence: Toward a model of emotion-specific influences on judgment and choice. Cognition and Emotion, 14, 473-493.

Lerner, J. S., \& Keltner, D. (2001). Fear, anger, and risk. Journal of Personality and Social Psychology, 81, 146-159.

Levenson, R. W., Ekman, P., \& Friesen. W. V. (1990). Voluntary facial expression generates emotion-specific nervous system activity. Psychophysiology, 27, 363-384.

Mackie, D. M., Devos, T., \& Smith, E. R. (2000). Intergroup emotions: Explaining offensive action tendencies in an intergroup context. Journal of Personality and Social Psychology, 79, 602-616.

Malatesta, C.Z. (1990). The role of emotions in the development and organization of personality. In A.T. Ross (Ed.), Nebraska symposium on motivation (Vol. 36, pp. 1-56). Lincoln, NE: University of Nebraska Press.

National Election Studies (2004) [Question file]. Ann Arbor, MI: University of Michigan, Center for Political Studies. Available from the National Election Studies Web site, http://www.umich. edu/ nes.

Olatunji, B. O., Lohr, J. M., \& Meunier, S. A. (2002. June 6-9). Emotional mediators of homophobia: Implications for construct and psychometric validity. Poster presented at the American Psychological Society 14th Annual Convention, New Orleans, LA.

Rozin, P., Lowery, L., Imada, S., \& Haidt, J. (1999). The moral/emotion (CAD) triad hypothesis: A mapping between the other-directed moral emotions, disgust, contempt, and anger, and
Shweder's three universal moral codes. Journal of Personality and Social Psychology 76, 574-586.

Schwartz, G. E., Brown, S., \& Ahern, G. L. (1980). Facial muscle patterning and subjective experience during affective imagery: Sex differences. Psychophysiology, 17, 75-82

Sears, D. O., \& Henry, P. J. (2003). The origins of symbolic racism. Journal of Personality and Social Psychology, 85, 259-275.

Shaver, P. R., Schwartz, J., Kirson, D., \& O’Connor, C. (1987). Emotion knowledge: Further exploration of a prototype approach. Journal of Personality and Social Psychology, 52, 1061-1086.

Sidanius, J., Pratto, F., \& Bobo, L. (1996). Racism, conservatism, affirmative action, and intellectual sophistication: A matter of principled conservatism or group dominance? Journal of Personality and Social Psychology, 70, 476-490.

Smith, C. A., \& Ellsworth, P. C. (1985). Patterns of cognitive appraisal in emotion. Journal of Personality and Social Psychology, 48, 813-838.

Smith, E. R. (1993). Social identity and social emotions: Toward new conceptualizations of prejudice. In D. M. Mackie \& D. L. Hamilton (Eds.), Affect, cognition, and stereotyping: Interactive processes in group perception (pp. 297-315). San Diego, CA: Academic Press.

Spielberger, C. D. (1996). State-trait anger expression inventory (STAXI) professional manual. Lutz, FL: Psychological Assessment Resources, Inc.

Spielberger, C. D., Sydeman, S. J., Owen, A. E., \& Marsh, B. J. (1999). Measuring anxiety and anger with the State-trait anxiety inventory (STAI) and the State-trait anger expression inventory (STAXI). In M. E. Maruish (Ed.), The use of psychological testing for treatment planning and outcomes assessment (2nd ed., pp. 993-1021). Mahwah, NJ: Lawrence Erlbaum Associates.

Stephan, W. G., \& Stephan, C. W. (1985). Intergroup anxiety. Journal of Social Issues, 41, 157-176.

Swim, J. K., Cohen, L. L., \& Hyers, L. L. (1998). Experiencing everyday prejudice and discrimination. In J. K. Swim \& C. Stangor (Eds.), Prejudice: The target's perspective (pp. 103-118). San Diego, CA: Academic Press.

Tiedens, L. Z., \& Linton, S. (2001). Judgment under emotional certainty and uncertainty: The effects of specific emotions on information processing. Journal of Personality and Social Psychology, 81, 973-988.

Van de Ven, P., Bornholt, L., \& Bailey, M. (1996). Measuring cognitive, affective, and behavioral 
components of homophobic reaction. Archives of Sexual Behavior, 25, 155-179.

Vanman, E. J., Paul, B. Y., Ito, T. A., \& Miller, N. (1997). The modern face of prejudice and structural features that moderate the effect of cooperation on affect. Journal of Personality and Social Psychology, 73, 941-959.

Vanman, E. J., Saltz, J. L., Nathan, L. R., \& Warren, J. A. (2004). Racial discrimination by lowprejudiced Whites: Facial movements as implicit measures of attitudes related to behavior. Psychological Science, 15, 711-714.

Vasquez, K., Keltner, D., Ebenbach, D., \& Banaszynski, T. (2001). Cultural variation and similarity in moral rhetorics: Voices from the Philippines and the United States. Journal of Cross-Cultural Psychology, 32, 93-120.

Weiner, B. (1993). On sin versus sickness: A theory of perceived responsibility and social motivation. American Psychologist, 48, 957-965.

Weiner, B., Perry, R. P., \& Magnusson, J. (1988). An attributional analysis of reactions to stigmas. Journal of Personality and Social Psychology, 55, 738-748.

Whitley, B. E. (1999). Right-wing authoritarianism, social dominance orientation, and prejudice. Journal of Personality and Social Psychology, 77, 126-134.

Word, C. O., Zanna, M. P., \& Cooper, J. (1974). The nonverbal mediation of self-fulfilling prophecies in interracial interaction. Journal of Experimental Social Psychology, 10, 109-120.

Paper received 1 December 2005; revised version accepted 5 June 2006.

\section{Biographical notes}

MOLLY PARKER TAPIAS received her BA in human biology and Latin American studies with Honors from Stanford University in 1995. She worked on policy research and public education for reproductive health issues until 1999. She received her $\mathrm{PhD}$ in psychology from the University of California, Berkeley, in 2005. Her research focuses on emotion, prejudice, stigma, and acceptance by significant others. She is a Consultant at Bain \& Company, Inc., in Palo Alto, California.

JACK GLASER received his BA in political science from the State University of New York at Albany in 1987, worked in the non-profit sector on public education problems until 1992, and received his $\mathrm{PhD}$ in psychology from Yale University in 1999. He is an experimental social psychologist whose research focuses on stereotyping, prejudice, and discrimination, generally, and specific topics including implicit bias and automatic correction, racial profiling, hate crime, ideology, and legal decision-making. $\mathrm{He}$ is an assistant professor at the Goldman School of Public Policy at the University of California, Berkeley, where he teaches courses in quantitative analysis, policy analysis, and prejudice and discrimination.

DACHER KELTNER received his $\mathrm{PhD}$ in social psychology in 1989 from Stanford University and currently is professor of psychology at $\mathrm{UC}$ Berkeley. His interests include the evolutionary and biological basis of human goodness, facial expression, power, and the relationship between morality and emotion.

KRISTEN VASQUEZ received her PhD in psychology in 2000 from the University of Wisconsin. Her interests include cultural influences on moral judgment and prejudice. She is an assistant professor of psychology at Alverno College in Milwaukee, where she serves as chair of the Global Studies Department and as co-director of the Behavioral Sciences Research Center.

THOMAS WICKENS is a professor of psychology at the University of California, Berkeley. 